\title{
ENDOTHELIAL STUNNING AND MYOCYTE RECOVERY AFTER REPERFUSION OF JEOPARDIZED MUSCLE: A ROLE OF L-ARGININE BLOOD CARDIOPLEGIA
}

Asatoshi Mizuno, $\mathrm{MD}^{\mathrm{a}}$

Rufus Baretti, $\mathrm{MD}^{\mathrm{a}}$

Gerald D. Buckberg, MD

Helen H. Young, $\mathrm{PhD}^{\mathrm{a}}$

Jakob Vinten-Johansen, $\mathrm{PhD}$

Xin-Liang Ma, MD, PhD

Louis J. Ignarro, $\mathrm{MD}^{\mathrm{b}}$
Ischemia and reperfusion may damage myocytes and endothelium in jeopardized hearts. This study tested whether (1) endothelial dysfunction (reduced nitric oxide release) exists despite good contractile performance and (2) supplementation of blood cardioplegic solution with nitric oxide precursor $\mathrm{L}$-arginine augments nitric oxide and restores endothelial function. Among 30 Yorkshire-Duroc pigs, 6 received standard glutamate/ aspartate blood cardioplegic solution without global ischemia. Twenty-four underwent 20 minutes of $37^{\circ} \mathrm{C}$ global ischemia. Six received normal blood reperfusion. In 18, the aortic clamp remained in place 30 more minutes and all received 3 infusions of blood cardioplegic solution. In 6 , the blood cardioplegic solution was unaltered; in 6 , the blood cardioplegic solution contained $\mathrm{L}$-arginine (a nitric oxide precursor) at $2 \mathrm{mmol} / \mathrm{L}$; in 6 , the blood cardioplegic solution contained the nitric oxide synthase inhibitor L-nitro arginine methyl ester (L-NAME) at $1 \mathrm{mmol} / \mathrm{L}$. Complete contractile and endothelial recovery occurred without ischemia. In jeopardized hearts, complete systolic recovery followed infusion of blood cardioplegic solution and of blood cardioplegic solution plus L-arginine. Conversely, contractility recovered approximately $\mathbf{4 0 \%}$ after infusion of normal blood and blood cardioplegic solution plus L-NAME. Postischemic nitric oxide production fell 50\% in the groups that received blood cardioplegic solution and blood cardioplegic solution plus L-NAME but was increased in the group that received blood cardioplegic solution $L$-arginine. In vivo endotheliumdependent vasodilator responses to acetylcholine recovered $75 \% \pm 5 \%$ of baseline in the blood cardioplegic solution plus L-arginine group, but less than $20 \%$ of baseline in other jeopardized hearts. Endothelium-independent smooth muscle responses to sodium nitroprusside were relatively unaltered. Myeloperoxidase activity (neutrophil accumulation) was similar in the blood cardioplegic solution (without ischemia) and blood cardioplegic solution plus L-arginine groups $(0.01 \pm 0.002$ vs $0.013 \pm 0.003 \mu \mathrm{g} / \mathrm{gm}$ tissue). Myeloperoxidase activity was raised substantially to $0.033 \pm 0.002$ $\mu \mathrm{g} / \mathrm{gm}$ after exposure to normal blood and to $0.025 \pm 0.003 \mu \mathrm{g} / \mathrm{gm}$ after infusion of blood cardioplegic solution and was highest at $0.053 \pm 0.01$ $\mu \mathrm{g} / \mathrm{gm}$ with exposure to blood cardioplegic solution plus L-NAME in

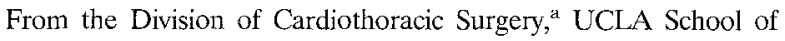
Medicine, Los Angeles, Calif; the Department of Cardiothoracic Surgery, Bowman Gray School of Medicine, WinstonSalem, N.C.; the Department of Emergency Medicine, Jefferson Medical College, Philadelphia, $\mathrm{Pa}$; and the Department of Pharmacology, ${ }^{b}$ UCLA School of Medicine, Los Angeles, Calif.

Rufus Baretti was supported in full by the Deutsche Forschungsgemeinschaft (Geman Research Foundation).

Read at the Seventy-sixth Annual Meeting of The American Association for Thoracic Surgery, San Diego, Calif., April 28-May 1, 1996.
Received for publication May 22, 1996; revisions requested August 6, 1996; revisions received August 30, 1996; accepted for publication Sept. 9, 1996.

Address for reprints: Gerald D. Buckberg, MD, UCLA School of Medicine, Division of Cardiothoracic Surgery, Room B2-375 CHS, 10833 Le Conte Ave, Los Angeles, CA 90095-1741.

J Thorac Cardiovasc Surg 1997;113:379-89

Copyright (C 1997 by Mosby-Year Book, Inc.

$0022-5223 / 97 \$ 5.00+0 \quad \mathbf{1 2 / 6 / 7 7 8 5 4}$ 


\section{jeopardized hearts. The discrepancy between contractile recovery and endothelial dysfunction in jeopardized muscle can be reversed by adding L-arginine to blood cardioplegic solution. (J Thorac Cardiovasc Surg 1997; 113:379-89)}

$E^{a}$ arly death may follow technically successful elective or emergency operations in patients with good ventricular performance. The causes of cardiac depression are complex and sometimes may involve injury of vascular endothelium. ${ }^{1}$ This may occur within minutes after reperfusion and may result in neutrophil-mediated reperfusion injury. Endothelial damage may also cause myocyte dysfunction because of imbalance between vasodilator (such as nitric oxide [NO]) and vasoconstrictor substances and precede myocyte injury in jeopardized hearts.

NO is produced from the amino acid L-arginine that combines with molecular oxygen and produces citrulline via constitutive NO synthase. If ischemiareperfusion injury causes endothelial dysfunction, ${ }^{2}$ subsequent release of NO decreases, ${ }^{3}$ vasorelaxation is altered, ${ }^{4}$ platelet aggregation is increased, ${ }^{5}$ and leukocyte adherence to vascular endothelium is enhanced with a concomitant increase in cytotoxic oxygen radical production. ${ }^{6}$ Impaired NO generation decreases the endogenous neutralization of superoxide radicals ${ }^{7}$ and may predispose jeopardized myocardium to exacerbated reperfusion injury and poor postischemic contractile performance. These adverse endothelial effects in regional ischemia were reduced by adding L-arginine to cold blood cardioplegic solution, but contractility remained depressed markedly. ${ }^{8}$

In this study, a model of damaged myocardium was produced by 20 minutes of unprotected normothermic ischemia (aortic clamping), followed by 30 minutes of protected ischemia with blood cardioplegic solution that completely restores contractile recovery. ${ }^{9}$ These solutions were either a standard amino acid-enhanced formulation or one supplemented with either L-arginine, the precursor to NO, or L-nitro arginine methyl ester (L-NAME), a competitive inhibitor of NO synthase. Results unmask a limitation of this blood cardioplegic solution that allows full recovery of postischemic contractile function, but produces endothelial dysfunction expressed as decreased receptor-dependent vasodilation and increased myocardial neutrophil accumulation in myocardium. These changes are reversed by adding L-arginine to the cardioplegic solution.

\section{Material and methods}

All animals received humane care in compliance with the "Principles of Laboratory Animal Care" formulated by the Institute of Laboratory Animal Resources and the "Guide for the Care and Use of Laboratory Animals" prepared by the Institute of Laboratory Animal Resources and published by the National Institutes of Health (NIH Publication no. 86-23, revised 1985).

Thirty Yorkshire-Duroc miniature pigs (24 to $26 \mathrm{~kg}$ weight, age 5 to 6 months) were premedicated (ketamine, $5 \mathrm{mg} / \mathrm{kg}$ intramuscularly) and anesthetized with pentobarbital, $30 \mathrm{mg} / \mathrm{kg}$, intravenously and subsequent bolus injections of sodium pentobarbital. Support with a volumecontrolled ventilator (Servo 900D, Siemens-Elema, Sweden) was started after tracheostomy and endotracheal intubation. The femoral artery and vein were cannulated and arterial blood gases measured to keep oxygen tension, carbon dioxide tension, and $\mathrm{pH}$ values within the normal range. Solid-state pressure transducer-tipped catheters (Millar Instruments, Inc., Houston, Tex.) were inserted into the left ventricle and carotid artery to measure left ventricular (LV) and aortic pressures, respectively, and a saline solution-filled catheter connected to a jugular vein pressure transducer recorded central venous pressure.

The pericardium was incised after median sternotomy and intravenous heparin (300 units/kg) was given. A saline solution-filled catheter in the left atrium was connected to a pressure transducer. A balloon-tipped catheter in the pulmonary artery measured cardiac output (thermodilution technique) and pulmonary artery pressure.

A $16 \mathrm{~F}$ femoral arterial catheter and $30 \mathrm{~F}$ right atrial catheter were placed. A dual-lumen aortic cannula measured delivery of blood cardioplegic solution and aortic pressure. The blood cardioplegic solution was hyperkalemic $(20 \mathrm{mg} \mathrm{KCl} / \mathrm{L})$, alkalotic (tromethamine), hypocalcemic $\left(0.2 \mathrm{mEq} / \mathrm{L} \mathrm{Ca}^{2+}\right)$, and enriched with glutamate/ aspartate as reported previously. ${ }^{10}$ The coronary sinus was cannulated transatrially for blood sampling, and the LV was vented. An octapolar impedance catheter (Webster, Anaheim, Calif.) was inserted into the LV apex. The correct position was determined by the phasic wave pattern in the individual electrode pairs. The conductivity of blood was determined periodically by a standardized conductance cuvette. The conductance signal was processed by a Leycom Sigma 5 signal conditioner and processor (Oegstgeest, The Netherlands). Parallel conductance of structures contiguous with the LV was periodically corrected by the hypertonic saline technique. ${ }^{11}$

Extracorporeal circulation was achieved with a membrane oxygenator (Sarns 1630 membrane oxygenator, Sarns, Ann Arbor, Mich.) and an extracorporeal pump (Sarns) with the circuit primed with $1000 \mathrm{ml}$ Plasma-Lyte solution (Baxter Healthcare Corp.), $700 \mathrm{ml}$ stored porcine packed red blood cells, and calcium chloride for normo- 


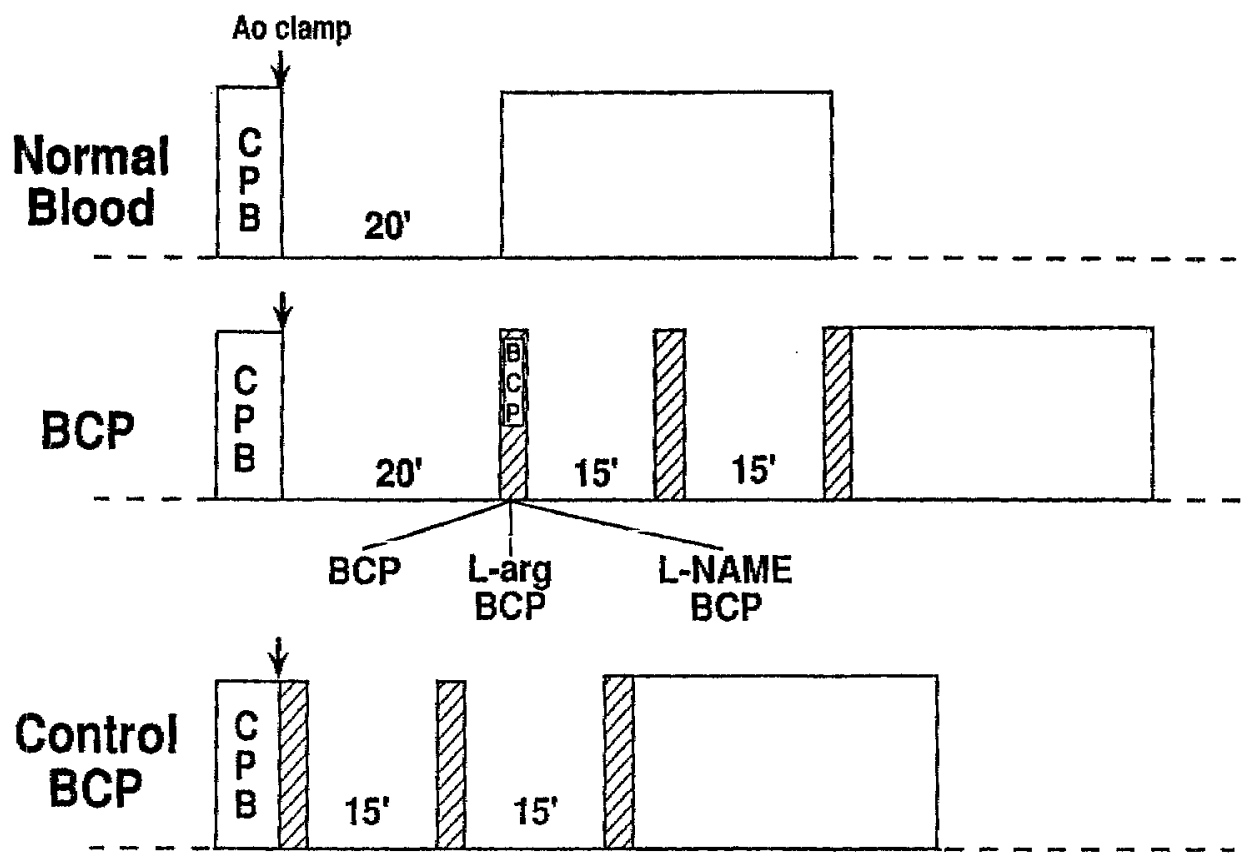

Fig. 1. Schematic diagram of the experimental protocol. The normal blood group was placed on bypass and subjected to 20 minutes of normothermic ischemia, followed by normal blood reperfusion. Blood cardioplegia $(B C P)$ groups were subjected to global ischemia and blood cardioplegic solution with or without L-arginine ( $L$-arg) or L-NAME. A control BCP group was not jeopardized by normothermic ischemia but received amino acid-enhanced blood cardioplegic solution.

calcemia (1.0 to $1.2 \mathrm{mmol} / \mathrm{L})$. Potassium, calcium, and $\mathrm{pH}$ were kept at normal levels.

Experimental protocol. In 30 pigs, cardiopulmonary bypass (CPB) was started at an oxygen tension of $300 \mathrm{~mm}$ $\mathrm{Hg}$ and an aortic pressure of 50 to $60 \mathrm{~mm} \mathrm{Hg}$ by adjusting pump flow to approximately $80 \mathrm{ml} / \mathrm{kg}$ per minute. The experimental protocol is shown in Fig. 1.

Control blood cardioplegic group. Six normal hearts without ischemia received the blood cardioplegia protocol (unjeopardized hearts; control BCP group).

\section{Ischemic groups}

NORMAL BLOOD REPERFUSION. Six pigs underwent 20 minutes of normothermic aortic clamping followed by reperfusion with normal blood. CPB was continued for 30 more minutes and final metabolic and functional measurements were made 30 minutes later.

BLOOD CARDIOPLEGIC SOLUTION REPERFUSION. In 18 pigs, the aorta was clamped for 20 minutes of normothermic ischemia followed by 30 minutes of arrest with the use of blood cardioplegia; all hearts received a $4: 1$ blood cardioplegic solution delivered at $200 \mathrm{ml} / \mathrm{min}$. The cardioplegia protocol included warm induction ( 2 minutes) followed by cold maintenance (repeated in 15 minutes) and infusion of warm reperfusate before unclamping.

BLOOD CARDIOPLEGIC SOLUTION WITHOUT NO-RELATED ADDITIVES. In six pigs, the blood cardioplegic solution did not contain NO-related agents (BCP group).

BLOOD CARDIOPLEGIC SOLUTION PLUS L-ARGININE. In six pigs, the final blood cardioplegic solution contained Larginine at $2 \mathrm{mmol} / \mathrm{L}$ (BCP plus L-arginine group).
BLOOD CARDIOPLEGIC SOLUTION PLUS L-NAME. In six pigs, the solution contained L-NAME ( $1 \mathrm{mmol} / \mathrm{L}$ blood cardioplegic solution) to inhibit the endogenous generation of NO by NO synthase (BCP plus L-NAME group).

Measurements. Global LV function before and after CPB was assessed by (1) Starling function curves and (2) pressure-volume analysis with end-systolic elastance. In Starling curves, preload was raised by continuously infusing blood intravenously at $4 \mathrm{ml} / \mathrm{kg}$ per minute while cardiac output and mean arterial and left atrial pressure were recorded. Cardiac output was determined by duplicate central venous injections of $3 \mathrm{ml}$ of $4^{\circ} \mathrm{C}$ saline solution, and left ventricular stroke work index (LVSWI) was calculated. LV systolic function was assessed from the linear end-systolic pressure-volume relationship during transient caval occlusions to obtain a series of evenly declining pressure-volume loops. With use of a video graphics program (SPECTRUM, Triton Technology, Inc., San Diego, Calif.), the end-systolic point for each loop was identified using the algorithm of Kono and associates. ${ }^{12}$ Linear regression was done on the corrected (parallel conductance) end-systolic pressure-volume points, and the slope and volume axis intercept were used to assess elastance and position of the pressure-volume relation. Chamber stiffness was calculated from the exponential end-diastolic pressure-volume relationship obtained during the same transient bicaval occlusion period and was described by the unitless coefficient or modulus of stiffness. Postbypass LV performance was expressed as percent of recovery from prebypass values. 


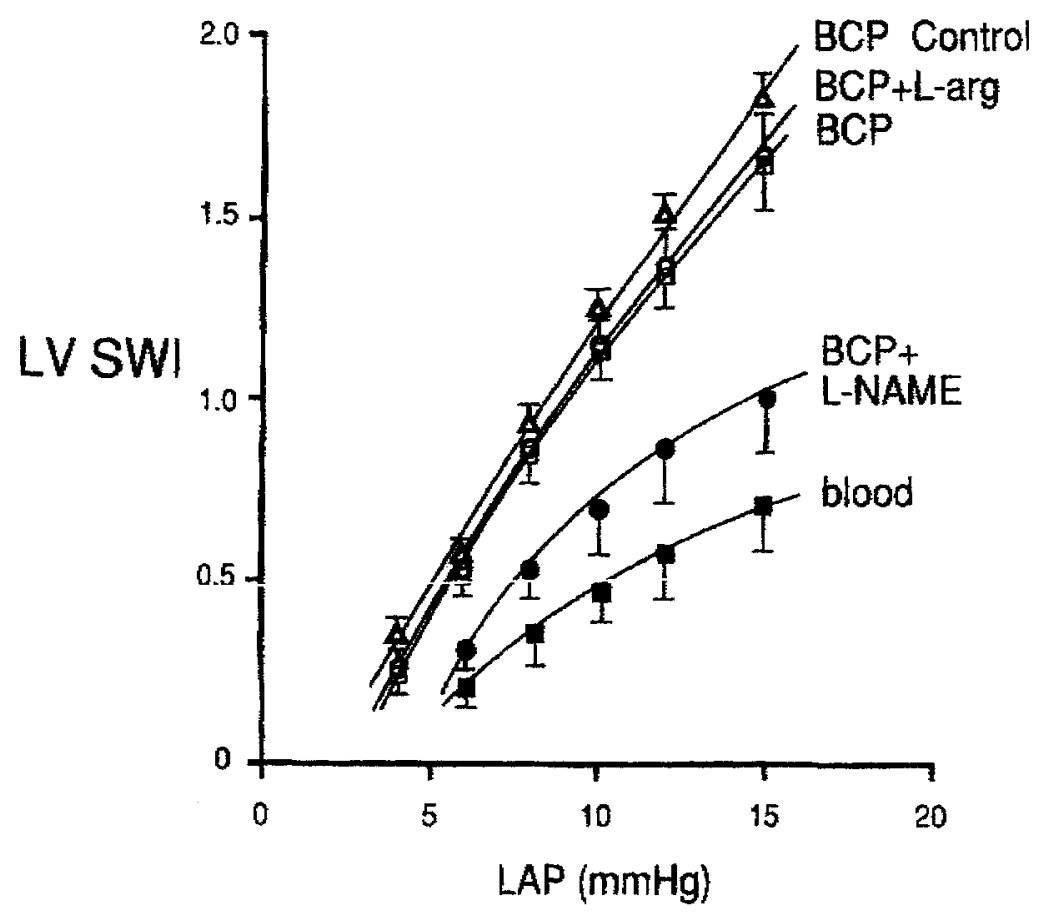

Fig. 2. LV performance assessed by Starling curves. $L A P$, Left atrial pressure; $B C P$, blood cardioplegic solution; blood, reperfusion with unmodified blood; $L$-arg, L-arginine.

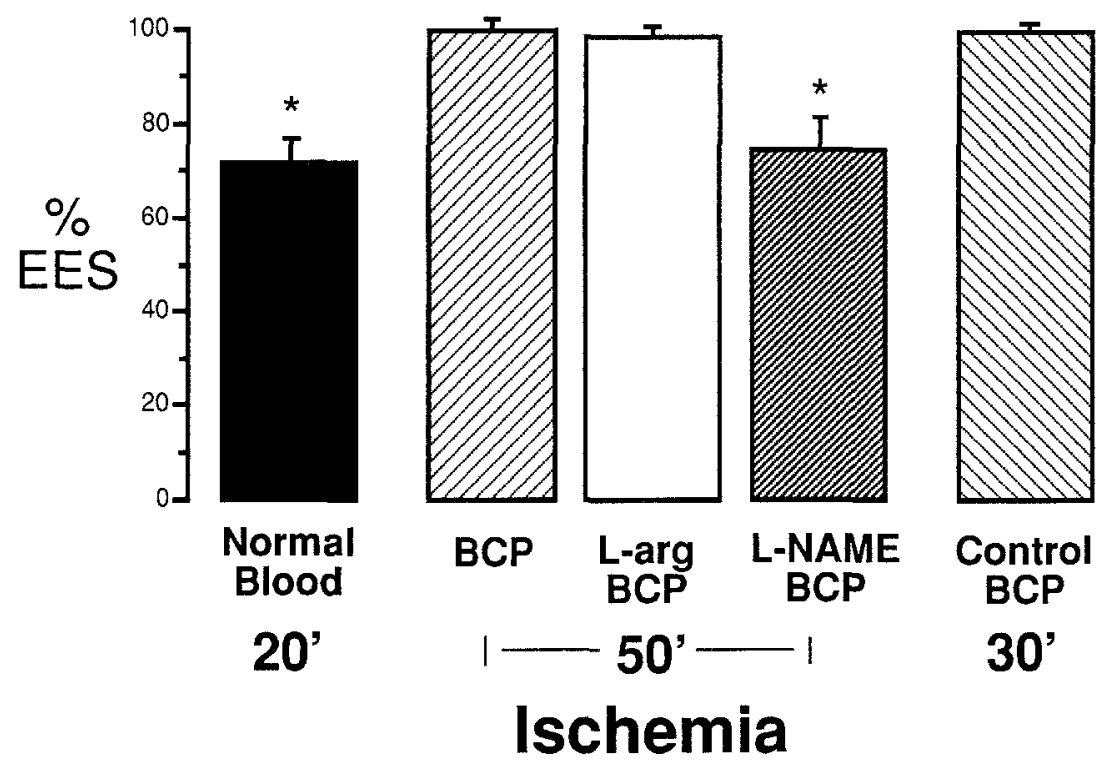

${ }^{*} p<0.05$ vs Normal Blood and L-NAME BCP

Fig. 3. Recovery of LV end-systolic elastance, expressed as a percent of preischemic control values. $E E S$, End-systolic elastance; other abbreviations as in Fig. 2.

In vivo coronary vascular responses. Coronary vascular responses to the stimulators of NO synthase acetylcholine (an endothelial receptor-dependent agonist) and nitroprusside (an endothelium-independent, smooth muscle agonist) were made before (preischemia, acetylcholine, nitroprusside only) and after the measurement protocol was completed (postischemia, acetylcholine, nitroprusside and A23187 infusions) by a constant flow technique. The 


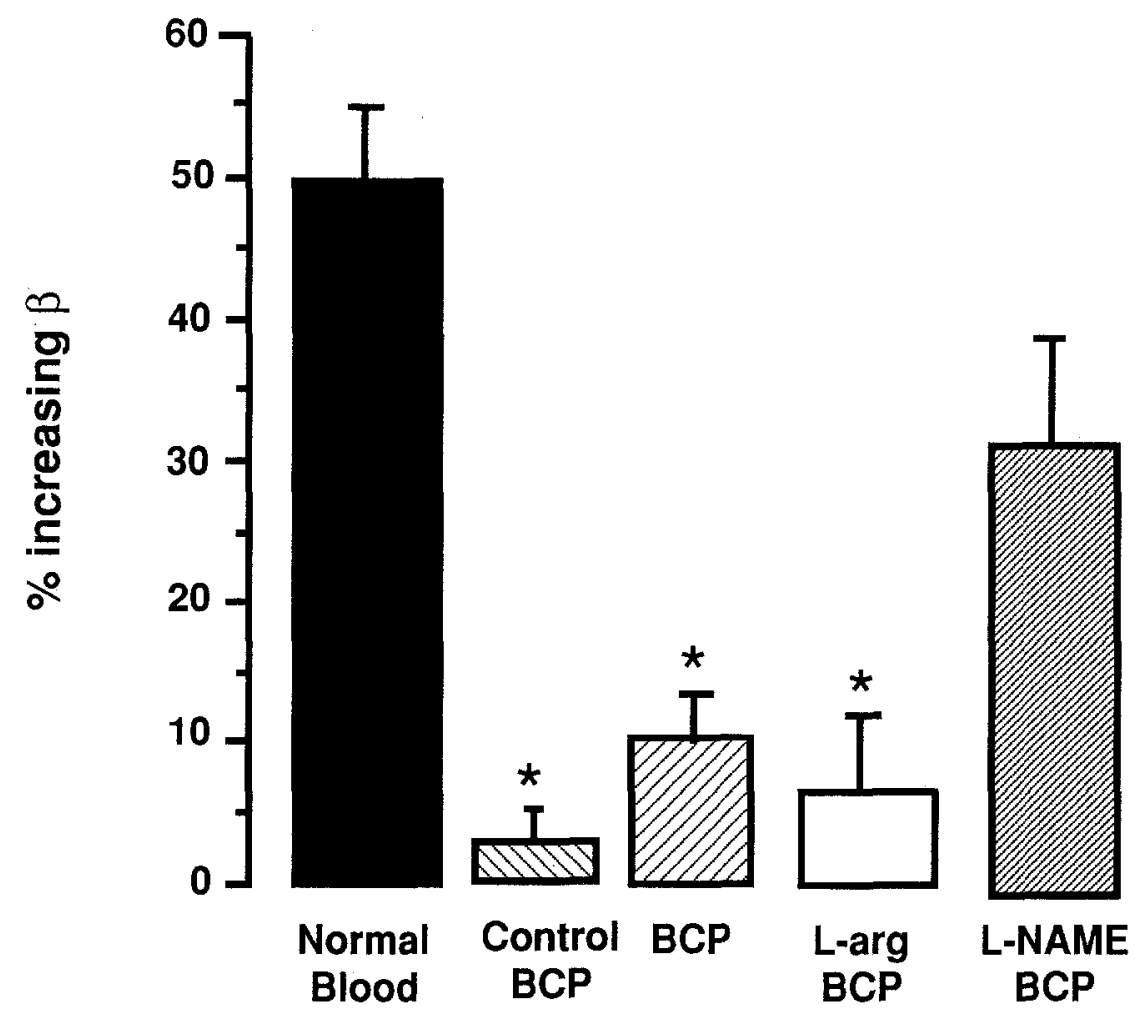

${ }^{*} p<0.05$ vs Normal blood and L-NAME BCP

Fig. 4. LV chamber stiffness, expressed as a percent increase from baseline control values in the $\beta$ coefficient. ${ }^{*} p<0.05$ versus normal blood group and BCP plus L-NAME group. Abbreviations as in Fig. 2.

aorta was clamped and the root perfused with blood at 50 $\mathrm{mm} \mathrm{Hg}$ (approximately $100 \mathrm{ml} / \mathrm{min}$ ). Heart rate was atrially paced at 170 beats/min. After 5 minutes' stabilization, $5 \mathrm{ml}$ acetylcholine $\left(10^{-4} \mathrm{ml} / \mathrm{L}\right)$ was injected as a bolus. After washout and stabilization, the endotheliumindependent agonist sodium nitroprusside followed by the endothelium-dependent receptor-independent calcium ionophore $\left(6.7 \times 10^{-5} \mathrm{~mol} / \mathrm{L}\right)$ were infused. Because of toxic effects of $\mathrm{A23187}$, baseline dilator responses were only made in nonischemic hearts. Coronary vascular responses were calculated as percent decrease in coronary pressure compared with baseline pressure responses.

Myocardial release of NO. Myocardial release of $\mathrm{NO}$ was analyzed from the aorta and coronary venous effluent. Coronary blood flow was the rate of pump delivery volume and the arteriovenous NO difference was used to calculate NO production. Samples were centrifuged immediately at $4^{\circ} \mathrm{C}$ and $3000 \mathrm{rpm}$ for 5 minutes and the plasma was stored in liquid nitrogen. NO concentration was determined by reconverting its oxidation end-products (nitrite, $\mathrm{NO}_{2}{ }^{-}$) and nitrate $\left(\mathrm{NO}_{3}\right)$ and measured by chemoluminescence (Chemiluminescence $\mathrm{NO}_{\mathrm{x}}$ Analyzer, model 2108, Dosibi Environmental Corp., Glendale, Calif.). ${ }^{13}$ Myocardial release of NO was expressed in millimolars per minute per $100 \mathrm{gm}$ of heart muscle.
Myeloperoxidase activity. Final transmural samples of LV myocardium (approximately $0.5 \mathrm{gm}$ ) from the anterior free wall were immediately frozen in liquid nitrogen until analyzed. Samples were analyzed for neutrophil-specific myeloperoxidase activity as previously described. ${ }^{8,14}$ Myeloperoxidase activity is expressed in units per gram of tissue. ${ }^{14}$

At the end of the experiment, the pigs were killed by bolus injection of $15 \mathrm{ml}$ cold hyperkalemic blood $(\mathrm{KCl}, 30$ $\mathrm{mEq} / \mathrm{L}$ ) and the hearts were harvested for determination of weight and myeloperoxidase activity.

Statistical analyses. All data are given as mean plus or minus standard error of the mean. Individual differences between baseline and reperfusion values were determined with the Student's $t$ test for paired data. Comparison of group functional and biochemical data was done by analysis of variance. Analyses were made with use of the StatView No. 2 software package 2.0 (Abacus Concepts, Berkeley, Calif.) on a Macintosh IIci computer (Apple Inc., Cupertino, Calif.). Significance was accepted at a $p<$ 0.05 level of probability.

\section{Results}

LV performance. Twenty minutes of normothermic ischemia and blood reperfusion recovered only 


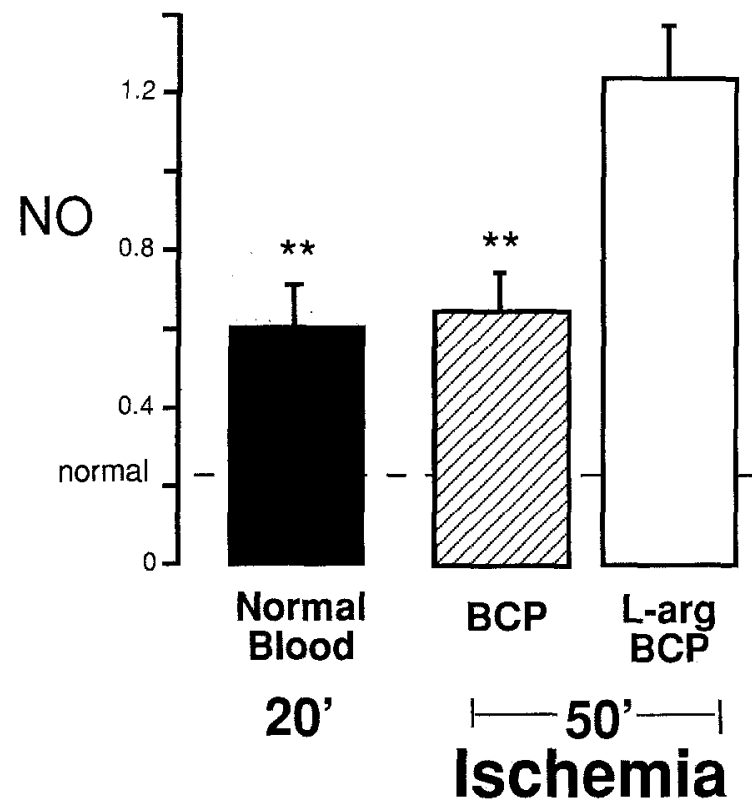

Fig. 5. Transmyocardial NO production $\left(\mathrm{NO}_{2}\right.$ plus $\left.\mathrm{NO}_{3}\right)$ after normothermic ischemia or during delivery of blood cardioplegic solution in absence of ischemia (BCP group) measured by chemoluminescence. Units are millimolars per minute per $100 \mathrm{gm}$ heart tissue. Abbreviations as in Fig. 2.

$37 \% \pm 7 \%$ of LVSWI at a left atrial pressure of 12 $\mathrm{mm} \mathrm{Hg}$ (Fig. 2). In the control BCP group, LVSWI recovered to $96 \% \pm 5 \%$ of baseline. Recovery was comparable in the unprotected ischemia plus BCP $(90 \% \pm 5 \%$ of baseline) and BCP plus L-arginine groups $(97 \% \pm 7 \%)$. This was greater than the recovery in the unmodified blood group. Conversely, the inclusion of L-NAME reversed this functional recovery to $56 \% \pm 4 \%$ of baseline, comparable to that with unmodified blood reperfusion.

Without ischemia, blood cardioplegic solution caused complete recovery of end-systolic elastance (Ees) relative to baseline $(100 \% \pm 2 \%)$. LV elastance (Ees) was $70 \% \pm 6 \%$ of baseline in the normal blood reperfused group (Fig. 3). After ischemia plus standard blood cardioplegic solution, recovery of elastance (Ees) was $100 \% \pm 4 \%$ and similar to that in the BCP plus L-arginine group $(98 \% \pm 3 \%)$, which exceeded that in the unmodified blood group. Conversely, L-NAME reduced recovery to $75 \% \pm 8 \%$, which was comparable to that in the normal blood group.

After normal blood reperfusion, the modulus of stiffness (unitless $\beta$ coefficient) rose $50 \% \pm 5 \%$ higher than baseline compared with no change in the control BCP group. In contrast, there was significantly less increase in stiffness in the BCP $(10 \% \pm 4 \%$ higher than baseline) and $\mathrm{BCP}$ plus L-arginine $(7 \% \pm 4 \%$ higher than baseline) groups (Fig. 4). The addition of L-NAME to blood cardioplegic solution raised postischemic stiffness to $31 \% \pm 7 \%$ higher than baseline, similar to that after unmodified blood reperfusion.

NO production. Immediately after ischemia, the BCP plus L-arginine group had the greatest NO production $(1.25 \pm 0.1 \mathrm{mmol} / \mathrm{min}$ per $100 \mathrm{gm})$, which was significantly greater than that in the unmodified blood reperfusion $(0.6 \pm 0.06)$ and BCP $(0.65 \pm 0.05)$ groups (Fig. 5). NO production fell progressively to normal when final vasodilator responses were measured (Fig. 6), suggesting that the $\mathrm{L}$-arginine effect on NO was absent. NO production was normal with $\mathrm{BCP}$ plus L-arginine and fell $50 \%$ lower than normal in the groups receiving normal blood and blood cardioplegic solution alone. NO production was not measured in the group treated with L-NAME because the acidic conditions of chemoluminescence assay falsely elevate NO concentration from L-NAME.

Coronary vasodilation with acetylcholine. Coronary endothelial receptor-dependent vasodilation recovered $75 \% \pm 10 \%$ of the baseline level in the BCP plus L-arginine group and $75 \% \pm 5 \%$ of the baseline level in the control (no antecedent ischemia) BCP group (Fig. 7, $A$ ). In contrast, vasodilator responses with acetylcholine were impaired to $25 \%$ $\pm 10 \%$ of baseline in the normal blood reperfusion group and to $20 \% \pm 5 \%$ of baseline in the BCP group. No vasodilation responses $(0 \%)$ were observed in the BCP plus L-NAME group.

Vasodilation to A23187. Under control conditions, the vasodilator response to A23187 averaged a $20 \%$ decrease in pressure during constant flow. In the unmodified (normal) blood reperfusion group, the hypotensive response to $\mathrm{A} 23187$ fell to approximately $50 \%$ of baseline values (Fig. $7, B$ ). In contrast, postischemic vasodilator responses to A 23187 were $75 \%$ of baseline in the BCP group and significantly greater in the $\mathrm{BCP}$ plus L-arginine group in which they slightly exceeded baseline vasodilator responses. With L-NAME treatment, vasodilator responses were reduced to approximately $60 \%$ of baseline and were significantly less than those in the BCP plus L-arginine group.

Vasodilation with nitroprusside. Endotheliumindependent vasodilation with nitroprusside recovered to $70 \%$ or more of baseline responses in all 


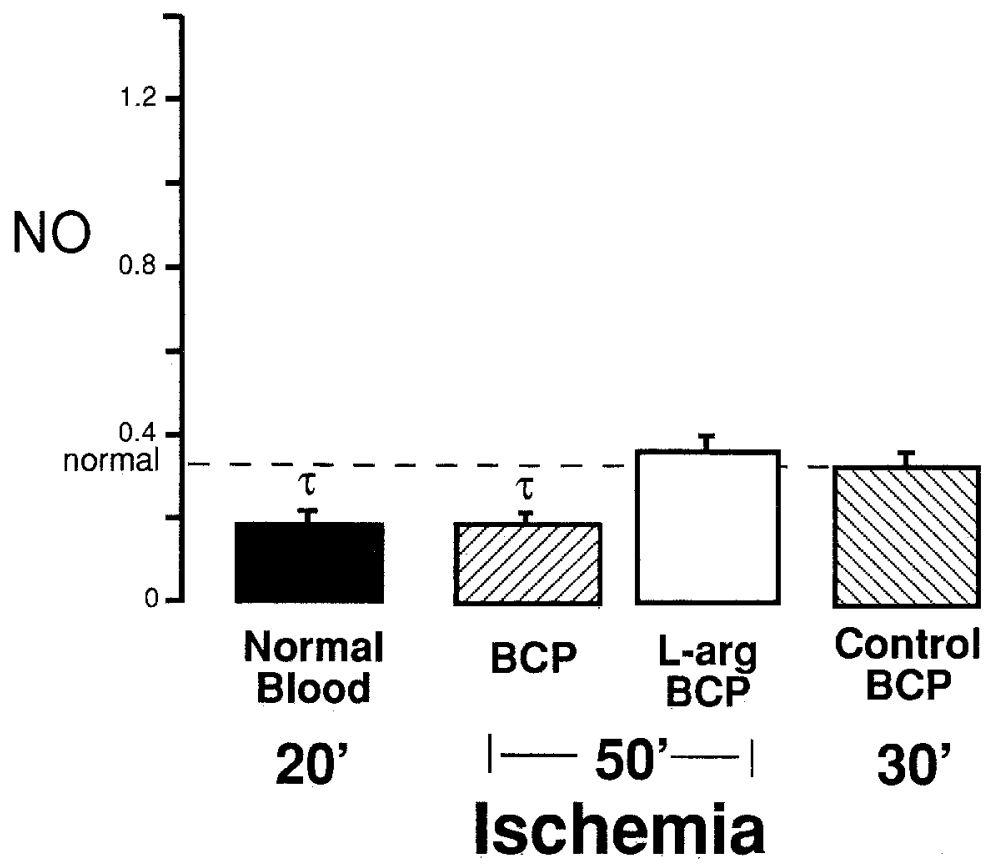

Fig. 6. Basal transmyocardial $\mathrm{NO}$ release $\left(\mathrm{NO}_{2}\right.$ plus $\left.\mathrm{NO}_{3}\right)$ after 30 minutes of reperfusion. Abbreviations as in Fig. 2.

groups, as shown in Fig. 7, $C$. The highest recovery was observed in the BCP plus L-NAME, BCP plus $\mathrm{L}$-arginine, and control BCP groups, despite absence of acetylcholine responses. Pressure was reduced by approximately $50 \%$ with L-NAME, which indicated a greater vascular resistance that may have been more fully relaxed by nitroprusside. Therefore the vasodilatory responses may have been greater in this group.

Myeloperoxidase activity. Myeloperoxidase activity averaged $0.033 \pm 0.002$ units/gm after unprotected ischernia and unmodified blood reperfusion and $0.025 \pm 0.003$ units/gm in the BCP group and rose to $0.053 \pm 0.01$ units $/ \mathrm{gm}$ after $\mathrm{BCP}$ plus L-NAME. In contrast, myeloperoxidase activity was significantly lower in the $\mathrm{BCP}$ plus $\mathrm{L}$-arginine $(0.013 \pm 0.003$ units $/ \mathrm{gm})$ and the control BCP groups $(0.01 \pm 0.002$ units/gm), as shown in Fig. 8 .

\section{Discussion}

In this study, the benefits of blood cardioplegic solution supplemented with the precursor to NO, L-arginine, ${ }^{15}$ were assessed in myocardium jeopardized by 20 minutes of normothermic global ischemia (unprotected ischemia) before protection with blood cardioplegic solution. These studies showed that a blood cardioplegic solution that allows com- plete myocardial systolic and diastolic functional recovery was associated with endothelial dysfunction primarily expressed as blunted receptor-mediated vasodilator responses to stimulators of NO synthase. Endothelial dysfunction was improved and neutrophil accumulation reduced by supplementation of the cardioplegic solution with L-arginine. L-arginine enhanced the transmyocardial production or release of NO. The competitive inhibitor of NO-synthase, L-NAME, reduced NO production and exacerbated postischemic contractile dysfunction, endothelial dysfunction, and myocardial neutrophil accumulation. These observations confirm the participation of basal NO in endogenous protection of the myocardium in surgical ischemia, ${ }^{16}$ cardioplegia, and reperfusion as observed by others with use of models of combined contractile and endothelial dysfunction. ${ }^{17}$

Tsao and Lefer ${ }^{18}$ showed that endothelial cell dysfunction occurs moments after reperfusion following regional ischemia and progresses with time. This dynamic endothelial cell dysfunction produces a reduction in NO generation, which leads to increased vasoconstriction and enhanced neutrophil adhesion and accumulation. Consistent with this concept of rapid endothelial cell damage during regional ischemia-reperfusion, Nakanishi and col- 
A

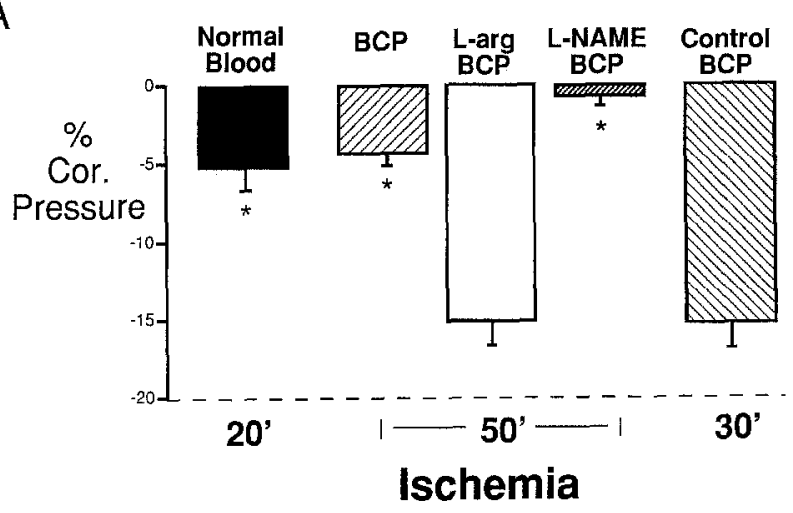

B

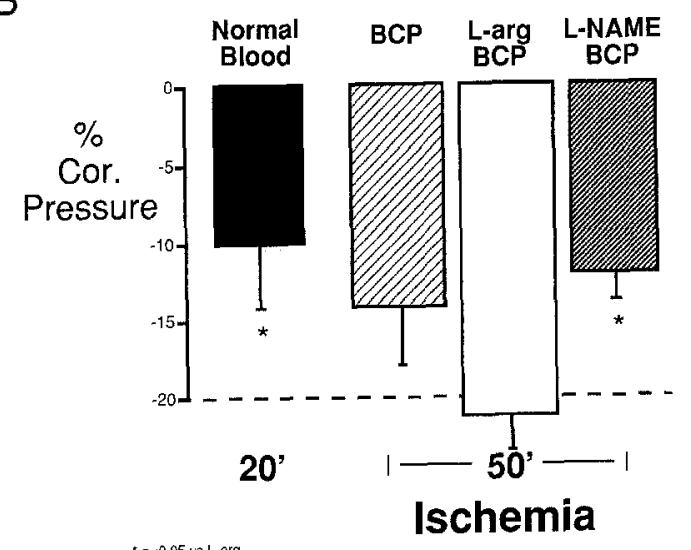

C

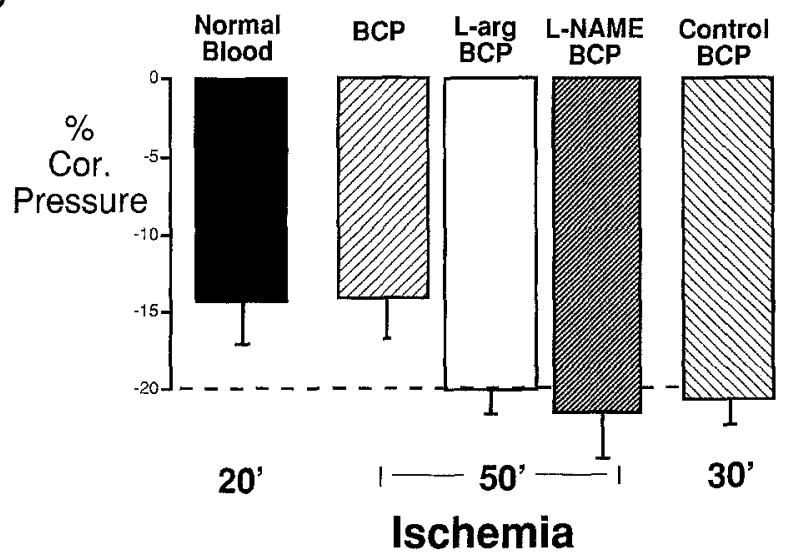

Fig. 7. Hypotensive responses to agonist stimulators of NO or direct smooth muscle dilators during constant aortic root flow. A, Hypotensive responses to endothelium-dependent, muscarinic receptordependent acetylcholine. B, Hypotensive response to the endothelium-dependent receptor-independent calcium ionophore A23187. C, Responses to the direct smooth muscle dilator sodium nitroprusside (SNP). Data represent percent of control (preischemic) hypotensive response. The dashed lines represent responses obtained in a series of normal hearts not subjected to ischemia, blood cardioplegic solution, or reperfusion. Cor., Coronary; other abbreviations as in Fig. 2.

leagues $^{14}$ demonstrated endothelial injury after blood cardioplegia in which morphologically and functionally apparent endothelial injury occurred during the reperfusion phase, rather than during 30 to 45 minutes of antecedent ischemia or blood cardioplegic arrest. Studies show endothelial injury (dysfunction) in neonatal hearts administered crystalloid cardioplegia, ${ }^{2,19}$ and this was associated with myocyte injury as well. In contrast, the ischemia imposed in the present study did not produce myocyte contractile dysfunction, but did produce endothelial dysfunction. However, vasodilator responses to the nonreceptor endothelial agonist A23187 were largely intact in the $\mathrm{BCP}$ group, suggesting that the dysfunction was at the muscarinic receptor or its signal transduction mechanism, rather than involving NO synthase or the vascular smooth muscle (sodium nitroprusside response). Therefore the current study suggests that (1) the endothelium may be more vulnerable to injury than the myocyte, or that endothelial injury precedes myocyte injury, and (2) injury to the endothelium (that is, stunning) does not always lead to contractile injury.

The lack of consistency between the presence of endothelial dysfunction and contractile dysfunction raises the question whether injury to the endothelium leads to loss of contractility. The initial interaction between endothelium and neutrophil may initiate neutrophil-mediated damage. However, with less severe injury, which may damage the 


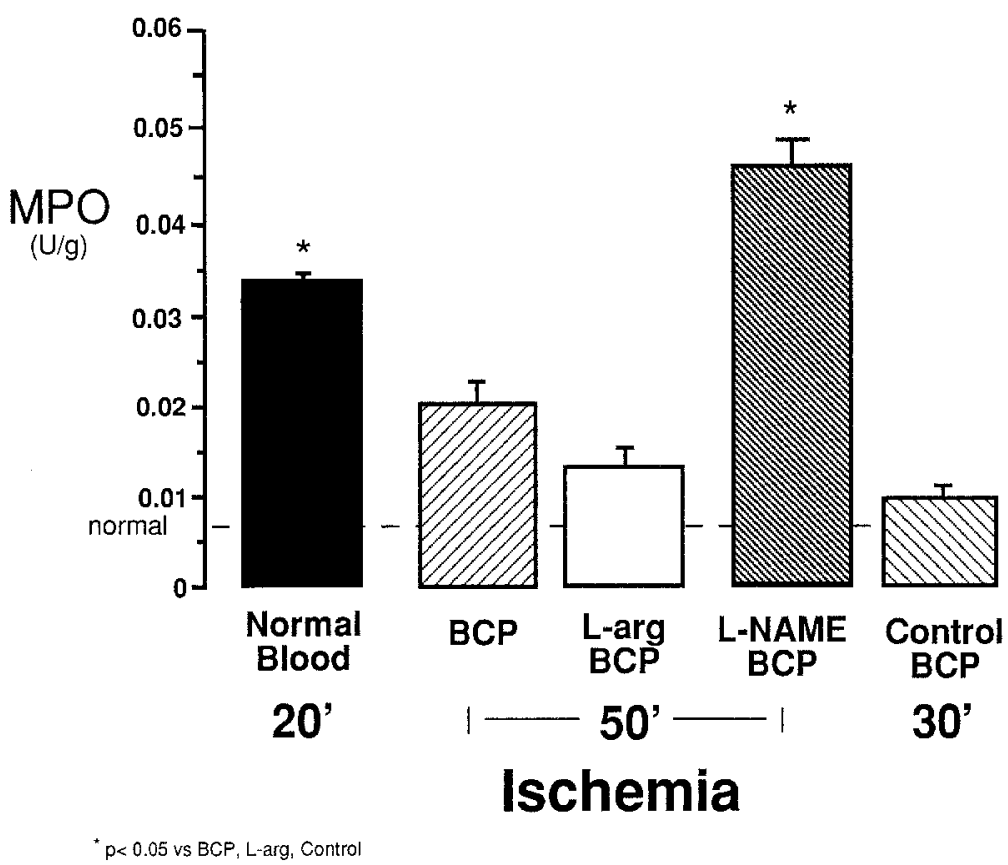

Fig. 8. LV anterior free wall myocardial myeloperoxidase (MPO) activity taken at the end of the reperfusion period. Abbreviations as in Fig. 2.

endothelium but not precipitate necrosis, the neutrophil component may not be important to stunning. Evidence suggests that neutrophils may not be involved in the pathogenesis of myocardial stunning. ${ }^{20}$ How endothelial dysfunction relates to contractile dysfunction in stunning requires further clarification.

The benefit of L-arginine supplementation in cardioplegic solution is predicated on incorporation of the NO precursor into cells and subsequent augmentation of NO production. ${ }^{21}$ It has been shown that supplemental L-arginine is taken up by vascular endothelial cells, ${ }^{15,22}$ particularly in cells starved of the amino acid. Enhanced uptake is accompanied by enhanced release of NO. Our data support this by showing that $\mathrm{L}$-arginine in blood cardioplegic solution augmented total nitrate/nitrite levels, largely representing NO. In addition, vasodilator agonists like acetylcholine stimulate both the uptake of $\mathrm{L}^{-}$ arginine and the release of $\mathrm{NO},{ }^{23}$ whereas depletion of L-arginine reduces the release of $\mathrm{NO}^{24} \mathrm{Ma}$ and associates ${ }^{25}$ and others showed that inhibition of basal release of NO with L-NAME increased neutrophil adherence to endothelium. This increased adherence was reversed completely by the addition of L-arginine, which suggests that endothelium-derived NO is an important intrinsic modulator of leukocyte adherence. ${ }^{26}$ In addition, Sato, Zhao, and Vinten-Johansen ${ }^{27}$ reported that L-arginine, but not D-arginine, inhibited neutrophil adherence to coronary endothelium, which was reversed by NO-synthase inhibitors. Accordingly, supplemental L-arginine has been shown to reduce necrosis and endothelial injury in models of coronary occlusionreperfusion ${ }^{28,29}$ and global ischemia followed by cardioplegia. $^{8,14}$ This protection is mediated by enhanced NO and targets primarily neutrophil-mediated damage. L-Arginine has no direct inhibitory effect on neutrophils. ${ }^{27}$ In this study, the severity of injury after ischemia and blood cardioplegia did not cause contractile dysfunction (myocyte), but produced endothelial cell dysfunction. L-Arginine in blood cardioplegic solution prevented both manifestations. The improved coronary vasodilator response was most likely not related to persistently high levels of L-arginine inas much as NO levels returned to baseline when postischemic vasodilator responses were tested. A more likely explanation is that $\mathrm{L}$-arginine reduced neutrophil accumulation (consistent with the myeloperoxidase data) and subsequent endothelial damage. L-Arginine may protect the endothelium through antineutrophil and direct quenching of superoxide by NO. ${ }^{30}$

An alternative mechanism of protection relates to 
the vasodilator action of NO. Perfusion defects may be related to increased vascular resistance as a result of impaired production of NO, producing a greater balance of vasoconstrictor agents such as endothelin-1 or enhanced neutralization of NO by superoxide radical anions. In the absence of NO, endothelin-1 production would increase, resulting in increased vascular resistance and decreased perfusion. These changes could explain the potential for perioperative vasospasm or graft closure in certain patients.

We conclude that (1) endothelial dysfunction can occur in the absence of contractile dysfunction, (2) $\mathrm{L}$-arginine supplementation reverses this endothelial injury possibly by enhancing NO production and inhibiting neutrophil-mediated damage, and (3) basal NO participates in endogenous protection during surgically related ischemia and reperfusion. Protection of the endothelium by L-arginine may reduce the contribution of endothelial injury to the progression of surgical reperfusion injury. Inclusion of L-arginine in cardioplegic solutions may be a novel, low-cost adjuvant.

\section{REFERENCES}

1. Seccombe JF, Schaff HV. Coronary artery endothelial function after myocardial ischemia and reperfusion. Ann Thorac Surg 1995;60:778-88.

2. Kawata H, Sawatari K, Mayer JEJ. Evidence for the role of neutrophils in reperfusion injury after cold cardioplegic ischemia in neonatal lambs. J Thorac Cardiovasc Surg 1991; 103:908-18.

3. Sawatari K, Kadoba K, Bergner KA, Mayer JEJ. Influence of initial reperfusion pressure after hypothermic cardioplegic ischemia on endothelial modulation of coronary tone in neonatal lambs. J Thorac Cardiovasc Surg 1991;101:777-82.

4. Furchgott RF. Role of endothelium in response of vascular smooth muscle. Circ Res 1983;53:557-73.

5. Furlong B, Henderson AH, Lewis MJ, Smith JA. Endothelium-delivered relaxing factor inhibits in vitro platelet aggregation. Br J Pharmacol 1987;90:687-92.

6. McCall T, White BJR, Boughton-Smith NK, Moncada S. Inhibition of FMLP-induced aggregation of rabbit neutrophils by nitric oxide [abstract]. Br J Pharmacol 1988;95:517P.

7. Rubanyi GM, Ho EH, Cantor EH, Lumma WC, ParkerBotelho LH. Cytoprotective function of nitric oxide: inactivation of superoxide radicals produced by human leukocytes. Biochem Biophys Res Commun 1991;181:1392-7.

8. Sato H, Zhao ZQ, McGee DS, Williams RE, Hammon JWJ, Vinten-Johansen J. Supplemental L-arginine during cardioplegic arrest and reperfusion avoids regional postischemic injury. J Thorac Cardiovasc Surg 1995;119:302-14.

9. Allen BS, Okamoto F, Buckberg GD, et al. Studies of controlled reperfusion after ischemia: XV--immediate functional recovery after six hours of regional ischemia by careful control of conditions of reperfusion and composition of reperfusate. J Thorac Cardiovase Surg 1986;92:621-35.
10. Rosenkranz ER, Okamoto F, Buckberg GD, Robertson JM, Vinten-Johansen J, Bugyi HI. Safety of prolonged aortic clamping with blood cardioplegia: III-aspartate enrichment of glutamate-blood cardioplegia in energy-depleted hearts after ischemic and reperfusion injury. $\mathrm{J}$ Thorac Cardiovasc Surg 1986;91:428-35.

11. Boltwood CM, Appleyard RF, Glantz SA. Left ventricular volume measurement by conductance catheter in intact dogs: parallel conductance volume depends on left ventricular size. Circulation 1989;80:1360-77.

12. Kono A, Maughan WL, Sunagawa K, Hamilton K, Sagawa K, Weisfeldt ML. The use of left ventricular end-ejection pressure and peak pressure in the estimation of the end-systolic pressure-volume relationship. Circulation 1984;70(6):105765.

13. Bush PA, Gonzalez NE, Griscavage JM, Ignarro LJ. Nitric oxide synthase from cerebellum catalyzes the formation of equimolar quantities of nitric oxide and citrulline from L-arginine. Biochem Biophys Res Commun 1992;185:960-6.

14. Nakanishi K, Zhao ZQ, Vinten-Johansen J, Hudspeth DA, McGee DS, Hammon JW Jr. Blood cardioplegia enhanced with nitric oxide donor SPM-5185 counteracts postischemic endothelial and ventricular dysfunction. J Thorac Cardiovasc Surg 1995;109:1146-54.

15. Palmer RMJ, Rees DD, Ashton AD, Moncada S. L-Arginine is the physiological precursor for the formation of nitric oxide in endothelium-dependent relaxation. Biochem Biophys Res Commun 1988;153:1251-6.

16. Williams MW, Taft CS, Ramnauth S, Zhao ZQ, VintenJohansen J. Endogenous nitric oxide (NO) protects against ischemia-reperfusion injury in the rabbit. Cardiovasc Res 1995;30:79-86.

17. Hiramatsu T, Forbess JM, Miura T, Mayer JE Jr. Effects of L-arginine and L-nitro-arginine methyl ester on recovery of neonatal lamb hearts after cold ischemia. J Thorac Cardiovasc Surg 1995;109:81-7.

18. Tsao PS, Lefer AM. Time course and mechanism of endothelial dysfunction in isolated ischemic-and hypoxic-perfused rat hearts. Am J Physiol 1990;259:H1660-6.

19. Aoki M, Kawata H, Mayer JE Jr. Coronary endothelial injury by cold crystalloid cardioplegic solution in neonatal lambs. Circulation 1992;86(Suppl):II346-51.

20. Juneau CF, Ito BR, del Balzo U, Engler RL. Severe neutrophil depletion by leukocyte filters or cytotoxic drug does not improve recovery of contractile function in stunned porcine myocardium [see comments]. Cardiovasc Res 1993;27:720-7.

21. Palmer RMJ, Ashton DS, Moncada S. Vascular endothelial cells synthesize nitric oxide from L-arginine. Nature 1988;333: 664-6.

22. Schmidt HH, Baeblich SE, Zernikow BC, Klein MM, Bohme E. L-Arginine and arginine analogues: effects on isolated blood vessels and cultured endothelial cells. $\mathrm{Br} \mathbf{J}$ Pharmacol 1990;101:145-51.

23. Bogle RG, Coade SB, Moncada S, Pearson JD, Mann GE. Bradykinin and ATP stimulate L-arginine uptake and nitric oxide release in vascular endothelial cells. Biochem Biophys Res Commun 1991;180:926-32.

24. Gold ME, Bush PA, Ignarro LJ. Depletion of arterial Larginine causes reversible tolerance to endothelium-dependent relaxation. Biochem Biophys Res Commun 1989;164: 714-21.

25. Ma XL, Weyrich AS, Lefer DJ, Lefer AM. Diminished basal 
nitric oxide release after myocardial ischemia and reperfusion promotes neutrophil adherence to coronary endothelium. Circ Res 1993;72;403-12.

26. Kubes P, Suzuki M, Granger N. Nitric oxide: an endogenous modulator of leukocyte adhesion. Proc Natl Acad Sci 1991; 88:4651-5.

27. Sato H, Zhao ZQ, Vinten-Johansen J. L-Arginine inhibits neutrophil adherence and coronary artery dysfunction. Cardiovasc Res 1996;31:63-72.

28. Weyrich AS, Ma X, Lefer AM. The role of L-arginine in ameliorating reperfusion injury after myocardial ischemia in the cat. Circulation 1992;86:279-88.

29. Patel VC, Yellon DM, Singh KJ, Neild GH, Woolfson RG. Inhibition of nitric oxide limits infarct size in the in situ rabbit heart. Biochem Biophys Res Commun 1993;194:234-8.

30. Hiramatsu T, Forbess JM, Miura T, Nomura F, Mayer JE Jr. Additive effects of L-arginine infusion and leukocyte depletion on recovery after hypothermic ischemia in neonatal lamb hearts. J Thorac Cardiovasc Surg 1995;110:172-9.

\section{Discussion}

Mr. Magdi H. Yacoub (London, United Kingdom). I have two questions. The first is, how did the authors measure pressure volumes? Was this an ex vivo model that just looked at the pressure versus the volume as in the Weber and Jenneke model, or did they really measure the pressure-volume relationship in an ejecting heart?

The second question is, one of the products of interaction between NO and oxygen radicals is the formation of peroxynitrite: do the authors think that had anything to do with the difference between myocardial and endothelial recovery, and have they measured a product like nitrothyroxine, for example?

Dr. Mizuno. We used a pressure-volume loop in in vivo models and measured the decline of the linear regression curve. Compared with control values, the linear regression curve was called $100 \%$, and after completion of the protocol we measured the percentage recovery of this level.

Mr. Yacoub. You used a conductance catheter?

Dr. Mizuno. Yes, a conductance catheter.

Dr. Jakob Vinten-Johansen. The question of nitrothyroxine and peroxynitrite is an excellent one, Mr. Yacoub, that stems from the controversial theory of NO potentially playing a dual role, that is, as a potent antineutrophil agent and a source of deleterious metabolites such as peroxynitrite. In the surgical setting used in the experiment in which endogenous NO levels are modulated, sufficient levells of NO may not have been achieved to produce significant amounts of peroxynitrite and other deleterious metabolites such as hydroxyl radicals. Therefore the beneficial effects of NO, including neutrophil inhibition, may have been predominantly expressed. Certainly, if NO achieves higher levels through overexpression, as it does in circulatory shock, peroxynitrite and its metabolites may exert a significant pathologic effect. We do not measure nitrothyroxine.

Dr. Frank W. Sellke (Boston, Mass.). Where was the NO that the authors measured, and how did they measure it?
Dr. Mizuno. We compared $\mathrm{NO}_{2}$ and $\mathrm{NO}_{3}$ with $\mathrm{NO}$ and used the chemoluminescence method.

Dr. Sellke. Did you look at baseline coronary perfusion to see whether the endothelial dysfunction correlated with a change in basal perfusion?

Dr. Mizuno. We made baseline measurements of coronary perfusion. After the reperfusion we measured the $\mathrm{NO}$ and in the injured group and the BCP group found the flow to have declined to less than the normal level, whereas L-arginine was maintained at the normal level.

Dr. Sellke. This is coronary perfusion, coronary blood flow, that the authors looked at?

Dr. Mizuno. We measured coronary flow by a controlled infusion of blood with the aorta clamped. We also measured NO production as we took a sample from the arterial side and the coronary sinus side. The production was the flow times the arteriovenous difference.

Dr. Sellke. My final comment is, how do the authors think L-arginine works? Do they think it is just increasing substrate availability, or is it reducing the inhibitory effects of glutamine and other inhibitors of NO synthase, or is it some other mechanism? Do they think it has a direct effect on white cell activation?

Dr. Mizuno. We think L-arginine increased the NO synthase pathway and raised NO production by this predominant pathway. This decreased white blood cell aggregation in the endothelium, as shown by the myeloperoxidase study, in which myeloperoxidase activity was very high with L-NAME. This NO production may also limit platelet aggregation and have a quenching effect on superoxide anion. Consequently, the role of L-arginine may be a broad spectrum of activities. We do not believe L-arginine has a direct effect on neutrophils, and acts via the NO synthase pathway.

Dr. Robert A. Guyton (Atlanta, Ga.). I want to return to the question of coronary vasodilation and how the authors measured perfusion and coronary flow. I am curious that they used pressure rather than flow or coronary resistance. Did the authors hold perfusion constant and look at pressure? Also with regard to Dr. Sellke's question, what was the baseline flow in the BCP group? Was it less than the baseline flow in the BCP group than in the BCP plus L-arginine group?

Dr. Mizuno. We maintained a coronary pressure of 50 $\mathrm{mm} \mathrm{Hg}$ and generally set a constant flow of $200 \mathrm{~mm} \mathrm{Hg}$ in control studies and in studies with blood cardioplegic solution with and without L-arginine. Consequently, any reduction in coronary pressure was a fall in perfusion after infusion of acetylcholine or nitroprusside. The baseline point was less after perfusion with L-NAME, so we may have overestimated the response in some cases. The drop in pressure was used to determine response.

Dr. Guyton. Do you know what the baseline differences were between the two groups?

Dr. Mizuno. During the preliminary experiments we did use reperfusion, but baseline pressure was the same before reperfusion and addition of the acetylcholine, calcium ionophore, or sodium nitroprusside. Consequently, there was no difference before drug injection. 